\title{
THE PEARLY EYE AT THE PAS, MANITOBA
}

WALTER KRIVDA, P.O. Box 864, The Pas, Manitoba. R9A $1 \mathrm{~K} 8$.

Collectors and students of butterflies are often surprised to find that this species ranges this far north in Manitoba. Two species of the genus Lethe (= Enodia) occur as far south as the Virginias while others occur in more temperate Japan and into the mainland of Asia. It is therefore somewhat of a surprise that a species of this group has penetrated this far north in Manitoba.

My experience with the Pearly Eye (Enodia portlandia borealis) in The Pas area goes back to 1951 when the first local specimen was collected along the old abandoned railway going through a sphagnum swamp about a mile east of town. It's a scarce species locally and seems sporadic in its distribution elsewhere.

In 1962 a considerable but very local flight occurred at the Big Eddy Indian Reservation. The location was in the ravine across the road from the cemetery on the hill overlooking the series of lakes. It's a moist grassy spot with Hazelnut shrubs present. Here in the company of Stephen and Franklin Chermock, on their way to collect in Churchill, a good study series was collected. This series is at present in the writer's collection at The Pas. The Chermocks also took a good study series.

It was somewhat of a surprise to take a specimen of the Pearly Eye at Reader Lake this summer. Here the habitat is very different from the preceding two habitats from which the species is known locally. It is a sandy, Jack PineWhite Spruce association. It may well be

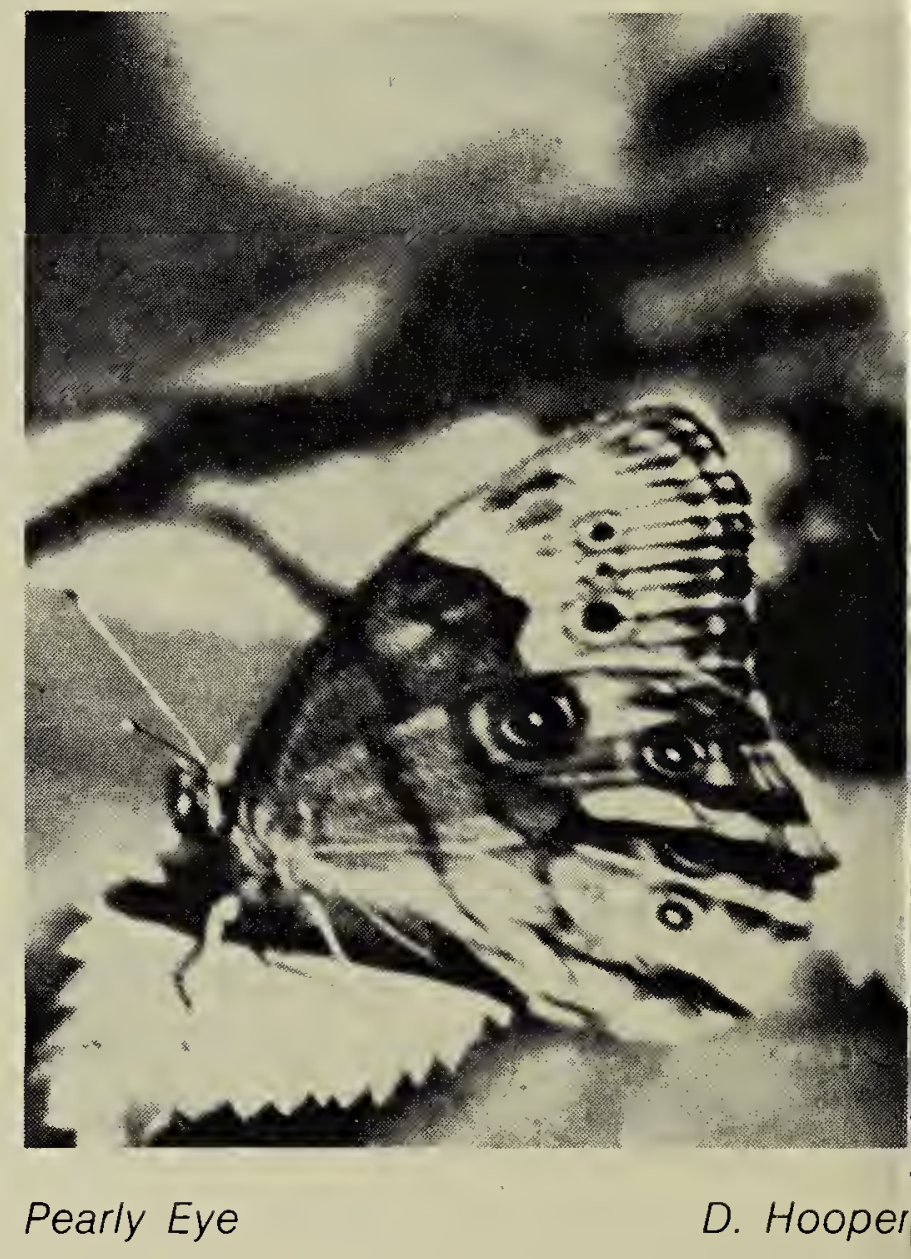

that the Pearly Eye inhabits only the narrow moist band of grasses and sedges along Reader Lake.

The caterpillar of this butterfly is known to feed on grasses. This zone has good stands of lush grasses growing in the rich black peat rimming the edges of the lake. This is the third. known colony of the Pearly Eye in The Pas area. More colonies will doubtless be found as the whole area is better explored. The Reader Lake colony is the most northern in Manitoba. This is about 12 miles north of The Pas. The species is rare locally; only three colonies have been discovered in 30 years of collecting in these parts. 